\title{
Policy Effectiveness Analysis of China's Circuit Breaker Mechanism
}

\author{
Wei Zhou (D), Wanying Rao, and Danxue Luo \\ School of Finance, Yunnan University of Finance and Economics, Kunming 650221, China \\ Correspondence should be addressed to Danxue Luo; 1034159312@qq.com
}

Received 2 May 2020; Accepted 31 July 2020; Published 28 September 2020

Academic Editor: Harish Garg

Copyright (C) 2020 Wei Zhou et al. This is an open access article distributed under the Creative Commons Attribution License, which permits unrestricted use, distribution, and reproduction in any medium, provided the original work is properly cited.

\begin{abstract}
From June to August 2015, China's security market suffered a severe decline due to the impact of the stock market crash. For this reason, the Shanghai Stock Exchange issued a notice on December 4, 2015, deciding to implement the circuit breaker mechanism on January 1, 2016. However, the mechanism was abolished only four days after its implementation. Therefore, this paper provides an empirical effectiveness analysis of this circuit breaker mechanism based on the nine CSI 300 industries using the regression discontinuity design method. The empirical results show that the implementation of the circuit breaker mechanism has led to the breakpoints of volatilities in nine industries and has significantly increased its market fluctuation. Moreover, we also find that the implementation of the circuit breaker mechanism has different impacts on the different industries, such as the effectiveness of the public, and consumer industries are at the medium level and show more stable fluctuations. Therefore, we suggest that the further circuit breaker mechanism in China's financial markets can be piloted from the public and consumer industries rather than directly implementing it on the whole CSI 300.
\end{abstract}

\section{Introduction}

The circuit breaker mechanism is a price-limiting mechanism that suspends trading for a while when an index rises or falls by a certain percentage to the trigger level. When applied to the financial markets, the circuit breaker mechanism is designed to prevent sharp fluctuation in asset prices [1], which has been applied in many financial markets. This paper will conduct an empirical study on the volatility data of nine industries in China's CSI 300, analyze the characteristics of the circuit breaker mechanism on different industries, draw some conclusions, and put forward some suggestions for further improving the system design, promoting the healthy development of the stock market, and improving China's stock market policy, which has certain practical significance.

Some scholars believe the circuit breaker mechanism can restrain the large fluctuations of the stock market, which is helpful to the stability of the market [2]. When the stock price fluctuation reaches the circuit breaker threshold, the suspension of trading is conducive to the transmission of information in the market and giving sufficient time for investment exchange and thinking [3], thus slowing down the irrational sentiment of investors and preventing the unexpected extreme volatility of the stock market [4]. Moreover, the circuit breaker mechanism is a period of suspension of trading that can provide a cooling-off period for investors' irrational behaviors [5], allowing investors the time to revalue securities and be conducive to promoting stock trading in an orderly manner, thus stabilizing the market and reducing market risks [6]. In addition, the circuit breaker mechanism can enhance the adequacy of information transmission and disclosure [7] and help investors to predict, so as to avoid excessive trading risks [8]. However, an opposite view holds that the essence of the circuit breaker mechanism could exacerbate the asymmetry of information $[9,10]$; this asymmetry would increase the volatility of stock prices and accelerate the triggering of the next circuit breaker [11-13]. Moreover, the circuit breaker mechanism fails to reduce intraday fluctuations and price declines [14], which is mainly caused by the overreaction of investors [15]. Besides, the circuit breaker mechanism interferes with the 
normal self-regulation of the market, which may distort the market price behavior and increase the systemic risk of the securities market [16]. The existence of the circuit breaker mechanism will make investors with an expectation that the market may fluctuate violently; in order to avoid the overnight trading risk, investors will carry out the operation in advance, thus aggravating the market fluctuation [17].

Through the above literature, we can find that their research subjects are the stock index of the market, without industry distinction. Considering that the stock price volatility, stock return rate, and other aspects of different industries are significantly different, thus we select the representative subindustry index as the research object in this paper.

In addition to the circuit breaker mechanism, there are many kinds of research on the factors affecting the stock price index, mainly focusing on macroeconomic indicators, including the exchange rate, interest rate, and inflation rate. Macroeconomic factors are the main reasons affecting stock market volatility $[18,19]$, stock prices, money supply, inflation rate, exchange rate, and industrial output, and other macroeconomic indicators have a long-term positive relationship with Chinese stock market prices [20]. Besides, there is a strong positive correlation between exchange rate and stock price fluctuation [21], and the rise of interest rate will cause the decline of the market index [22]. Moreover, the inflation rate has a strong correlation with the stock market volatility [23] and had the opposite effect on the long-term and short-term returns of the stock market [24], which has a great relationship with the period in which it is located [25].

We can find that the above literature mainly studies the influence of macroeconomic factors on the stock index. Besides, there are few studies on the impact of other markets on the Chinese stock market. Thus, we will take some macroeconomic factors and other major capitalist stock market indexes into account in the empirical study of this paper and provide some references for the Chinese government to reimplement the circuit breaker mechanism or other similar policies.

To achieve the above aims, the remainder of this paper is organized as follows: sections 2 and 3, respectively, present the data selection and methodology of the empirical study in this paper. Section 4 analyzes the empirical study and derives some empirical results. Finally, the conclusions are given in section 5 .

\section{Data Selection}

Based on the above analysis, the purpose of this paper is to explore the policy effect of the circuit breaker mechanism from the perspective of an individual industry. Therefore, we first introduce the volatility data of CSI 300 nine industry indices, the RMB exchange rate index, and the Dow Jones index of the United States in this section, and the research method will be introduced in the next section.
In China, the circuit breaker mechanism is taking the CSI 300 index as the circuit breaker benchmark index. The CSI 300 index is an index jointly published by the Shanghai and Shenzhen stock exchanges on April 8, 2005, to reflect the overall trend of the A-share market. The CSI 300 index can be divided into nine representative industry indices including material, telecommunications, industry, public, finance, energy, consumption, information, and pharmaceutical industry. Historical volatility can reflect market volatility. In order to study the policy effect of the circuit breaker mechanism on nine industries, we choose four kinds of volatility data because the four kinds of volatility data can more comprehensively reflect the volatility of various industries, and the volatilities calculated according to different cycles contain broader information.

When studying the policy effect of the circuit breaker mechanism, we should consider the cross-influence of other exogenous factors. When the breakpoint of volatility occurs in nine industries, if other exogenous factors also affect the breakpoint of volatility, the breakpoint cannot be fully attributed to the implementation of the circuit breaker mechanism, which will lead to biased estimation of policy effect. Through the literature analysis in the previous section, we can find that macroeconomic indicators have an impact on the stock index, and there are few studies on the impact of other markets on the Chinese stock market. Therefore, the representative RMB exchange rate index and the Dow Jones index in the US stock market are selected as exogenous factors to increase the accuracy and validity of the research results in this paper.

Based on the above analysis, the data in this paper are selected as follows: all data used in this paper are from the Wind database, including data from July 2015 to June 2016 for a year, with a total of 9,310 observations. The first trading day after the implementation of the circuit breaker mechanism is defined as 0 and the range of running variables for the whole sample is $(-125,119)$. Specifically, this paper uses four kinds of the volatility of CSI 300 nine industry indices as result variables; they are hv5, hv15, hv30, and hv50 (the volatility in the wind is calculated as follows: $\left\{\sum\left[\left(R_{i}-\sum R_{i} / N\right)^{2}\right] /(N-1)\right\}^{0.5}$, where $\mathrm{iR}$ is the logarithmic rate of return within the interval), where hv5, hv15, hv30, and hv50 represent the historical volatility calculated in cycles of 5 days, 15 days, 30 days, and 50 days, respectively. DOW and CFETS are taken as covariates. DOW represents the U.S. Dow Jones index, we selected the logarithmic yield of the daily closing price of the Dow Jones index. CFETS represents the RMB exchange rate index of China foreign exchange trade system; in this paper, we selected the logarithmic yield of the daily closing price of the RMB exchange rate index.

Table 1 shows the basic description of the observed values in this paper; columns 2-6 represent the number of observed values, mean value, standard deviation, minimum value, and maximum value, respectively. There are 245 data sets for each type of volatility in nine industries and 245 data sets for the U.S. Dow Jones index and the RMB exchange rate index of China, respectively. 
TABLE 1: The basic description of the variables.

\begin{tabular}{|c|c|c|c|c|c|}
\hline & Obs. & Mean & Std. Dev. & Min. & Max. \\
\hline \multicolumn{6}{|c|}{ Material industry } \\
\hline hv5 & 245 & 0.408 & 0.238 & 0.081 & 1.199 \\
\hline hv15 & 245 & 0.445 & 0.188 & 0.157 & 0.881 \\
\hline hv30 & 245 & 0.461 & 0.164 & 0.206 & 0.768 \\
\hline hv50 & 245 & 0.475 & 0.141 & 0.238 & 0.768 \\
\hline \multicolumn{6}{|c|}{ Telecommunications industry } \\
\hline hv5 & 245 & 0.394 & 0.266 & 0.047 & 1.415 \\
\hline hv15 & 245 & 0.432 & 0.234 & 0.108 & 1.008 \\
\hline hv30 & 245 & 0.450 & 0.218 & 0.152 & 0.844 \\
\hline hv50 & 245 & 0.469 & 0.197 & 0.175 & 0.856 \\
\hline \multicolumn{6}{|l|}{ Industry } \\
\hline hv5 & 245 & 0.394 & 0.255 & 0.042 & 1.253 \\
\hline hv15 & 245 & 0.433 & 0.226 & 0.112 & 1.005 \\
\hline hv30 & 245 & 0.451 & 0.206 & 0.174 & 0.868 \\
\hline hv50 & 245 & 0.470 & 0.182 & 0.200 & 0.825 \\
\hline \multicolumn{6}{|c|}{ Public industry } \\
\hline hv5 & 245 & 0.313 & 0.213 & 0.013 & 0.996 \\
\hline hv15 & 245 & 0.349 & 0.190 & 0.090 & 0.859 \\
\hline hv30 & 245 & 0.367 & 0.177 & 0.127 & 0.743 \\
\hline hv50 & 245 & 0.388 & 0.163 & 0.142 & 0.676 \\
\hline \multicolumn{6}{|c|}{ Finance industry } \\
\hline hv5 & 245 & 0.305 & 0.211 & 0.057 & 1.125 \\
\hline hv15 & 245 & 0.335 & 0.174 & 0.071 & 0.812 \\
\hline hv30 & 245 & 0.351 & 0.156 & 0.108 & 0.655 \\
\hline hv50 & 245 & 0.367 & 0.137 & 0.140 & 0.628 \\
\hline \multicolumn{6}{|c|}{ Energy industry } \\
\hline hv5 & 245 & 0.347 & 0.214 & 0.021 & 1.145 \\
\hline hv15 & 245 & 0.385 & 0.173 & 0.118 & 0.805 \\
\hline hv30 & 245 & 0.402 & 0.153 & 0.168 & 0.675 \\
\hline hv50 & 245 & 0.418 & 0.133 & 0.202 & 0.653 \\
\hline \multicolumn{6}{|c|}{ Consumption industry } \\
\hline hv5 & 245 & 0.318 & 0.917 & 0.067 & 1.006 \\
\hline hv15 & 245 & 0.342 & 0.171 & 0.136 & 0.889 \\
\hline hv30 & 245 & 0.355 & 0.158 & 0.160 & 0.734 \\
\hline hv50 & 245 & 0.367 & 0.144 & 0.195 & 0.660 \\
\hline \multicolumn{6}{|c|}{ Information industry } \\
\hline hv5 & 245 & 0.450 & 0.247 & 0.064 & 1.277 \\
\hline hv15 & 245 & 0.487 & 0.209 & 0.143 & 0.932 \\
\hline hv30 & 245 & 0.503 & 0.192 & 0.215 & 0.837 \\
\hline hv50 & 245 & 0.520 & 0.173 & 0.235 & 0.802 \\
\hline \multicolumn{6}{|c|}{ Pharmaceutical industry } \\
\hline hv5 & 245 & 0.351 & 0.235 & 0.069 & 1.163 \\
\hline hv15 & 245 & 0.376 & 0.204 & 0.136 & 0.931 \\
\hline hv30 & 245 & 0.392 & 0.187 & 0.163 & 0.789 \\
\hline hv50 & 245 & 0.407 & 0.168 & 0.171 & 0.735 \\
\hline DOW & 245 & 0.00004 & 0.011 & -0.040 & 0.036 \\
\hline CFETS & 245 & 00003 & 0.002 & -0.012 & 0.018 \\
\hline
\end{tabular}

\section{Methodology}

The regression discontinuity design (RDD) is close to local randomized trials, so it can effectively identify the causal relationship of policies and solve endogenous problems [26]. The RDD method was first proposed by Thistlethwaite and Campbell [27]; it is a kind of quasiexperimental design and a method of experimental treatment under more natural conditions. Among the measurement methods to identify causal effects, the RDD method is mostly used to study the impact of policies and regulations [28]. Therefore, we choose the RDD method as an empirical tool to evaluate the policy effect of the circuit breaker mechanism adopted by China's stock market on the nine industry indexes of CSI 300.

In the RDD method, when the variables are continuous, the research individuals which are less than the breakpoint can act as the control group to reflect the situation that the individuals do not accept the processing so that the individual differences near the breakpoint can well reflect the causal relationship between the processing variables and economic variables. The RDD can be divided into the Sharp Regression Discontinuity (SRD) and the Fuzzy Regression 
Discontinuity (FRD) according to whether the probability of the driving variable entering the treatment group equals 1 . Since the circuit breaker mechanism was implemented on the accurate day of January 4, 2016, this paper adopts the SRD model for empirical analysis.

Referring to Lee and Lemieux [29], we first introduce the following model:

$$
\begin{aligned}
D_{t} & =0, \quad \text { if } t_{i}<0, \\
\text { or } D_{t} & =1, \quad \text { if } t_{i} \geq 0 . \\
y & =\alpha+\tau D_{t}+f\left(t_{i}\right)+\xi W+\varepsilon_{i},
\end{aligned}
$$

where $D_{t}$ is the policy dummy variable, $t_{i}$ is the driving variable, $y$ is the outcome variable, and $W_{i}$ is the covariates. $\alpha$ is a constant, $\tau$ and $\xi$ are the parameters to be estimated, and $e_{i}$ is the residual term.

In equation (1), $D_{t}$ is a discontinuous function of $t_{i}$, and " 0 " is a breakpoint. $D_{t}$ indicates whether the circuit breaker mechanism is implemented or not. The dummy variable has a value of 1 , indicating that the circuit breaker has been implemented. When the value of the dummy variable is equal to 0 , the circuit breaker mechanism has not been implemented.

In equation (2), $f\left(t_{i}\right)$ is a polynomial that represents the relationship between the driving variable time and whether the circuit breaker mechanism is implemented. $W$ is a variable that contains DOW and CFETS. The coefficient $\tau$ of $D_{t}$ is the local average treatment effect (LATE) that needs to be estimated.

The estimation of $\tau$ can be divided into the parametric regression method and the nonparametric regression method. The former generally conducts the polynomial estimation while the latter adopts weighted local linear regression $[30,31]$. Since parametric regression is dependent on the specific function form, this paper will use nonparametric regression to estimate $\tau$.

Nonparametric estimation does not make assumptions about the function form near the breakpoint. The weighted local linear regression method is adopted for subsamples within the optimal bandwidth, the essence of weighted local linear regression is to conduct the weighted ordinary least square (OLS) method in a small field $(0-h, 0+h)$, and the weight is calculated by the kernel function [32].

The main idea is

$$
\min _{|\rho, \varphi, \sigma, \mu|} \sum_{i=1}^{m} K \cdot \frac{t_{i}}{h} \cdot\left(y-\rho-\varphi t_{i}-\sigma D_{t}-\mu \cdot t_{i} \cdot D_{t}\right)^{2},
$$

where $\mathrm{K}$ represents the kernel function; $h$ is the bandwidth; $y_{t}$ is the outcome variable, which represents the volatility in this paper; $t_{i}$ represents time; $\rho, \varphi, \sigma$, and $\mu$ are the parameters to be estimated; and $D_{t}$ is the dummy variable.

The kernel function is divided into triangle kernel density function and rectangle kernel density function. In the triangle kernel density function, the observed values near the breakpoint have the greater weights than other observed values; however, in the rectangle kernel density function, all the observed values have the same weights.
An important issue of nonparametric estimation is to determine the optimal bandwidth. In this paper, the method discussed by Imbens and Kalyanaraman [33] (IK method) is used to determine the optimal bandwidth. We provide more details about their application and comparison in the next section, which also fully shows the difference between the nine industry indices.

\section{Empirical Study}

Based on the four kinds of volatility on the nine industry indices, the U.S. Dow Jones index, and the RMB exchange rate index, we use the RDD method to conduct empirical research. In this section, the empirical results are shown in Tables 2 and 3 and Figures 1-9. The robustness and validity of the estimated results are presented in Tables 3-5.

4.1. Empirical Results. Before we conduct the nonparametric regression, we first determine the optimal bandwidth. Table 2 shows the optimal bandwidth for each volatility data in nine industries using the IK method. Then, we show the changes in the volatilities before and after the implementation of the circuit breaker in the form of graphs.

Figures 1-9 present the RDD results for the four kinds of volatility on nine industries using the optimal bandwidth without covariates. From Figures 1-9, we can find that on the implementation day of the circuit breaker mechanism, the four kinds of volatility in nine industries show breakpoints and significant jumps, especially the hv5 and hv15, which reflects the causal relationship between the circuit breaker mechanism and the industry volatilities; the implementation of the circuit breaker mechanism increases the fluctuation of nine industries. However, the specific increment of volatilities still depends on the estimate of LATE.

Table 3 shows the specific estimation results of LATE. The first row under each volatility represents the estimated results under the triangle kernel function. It can be found that the estimation results are all positive; it is suggested that the implementation of the circuit breaker mechanism has increased rather than decreased the fluctuation in all nine industries. For example, in the material industry, the implementation of the circuit breaker mechanism has led to an increase of about $36.9 \%, 16.4 \%, 8.7 \%$, and $6.6 \%$ in the hv5, hv15, hv30, and hv50, respectively.

Moreover, from Table 3, we can find that after the implementation of the circuit breaker mechanism, the increase of hv5 in the pharmaceutical industry is the largest at $44.0 \%$ while that of the telecommunications industry is the smallest at $17.1 \%$. The increase of hv15 in the industry is the largest while that of the telecommunications industry is the smallest, $17.7 \%$ and $10.3 \%$, respectively. The increase of hv30 in the information industry is the largest at $10.2 \%$ while that of the financial and energy industry is the smallest at $5.2 \%$. The increase of material industry hv50 is the largest while that of the finance industry is the smallest, $6.6 \%$ and $3.2 \%$, respectively. 
TABLE 2: The optimal bandwidth for all observations.

\begin{tabular}{|c|c|c|c|c|c|}
\hline \multirow{2}{*}{\multicolumn{2}{|c|}{$\begin{array}{l}\text { Material industry } \\
\text { Optimal bandwidth }\end{array}$}} & \multicolumn{2}{|c|}{ Telecommunications industry } & \multicolumn{2}{|c|}{ Industry } \\
\hline & & \multicolumn{2}{|c|}{ Optimal bandwidth } & \multicolumn{2}{|c|}{ Optimal bandwidth } \\
\hline hv5 & 4.27 & hv5 & 4.02 & hv5 & 4.04 \\
\hline hv15 & 3.22 & hv15 & 2.98 & hv15 & 2.90 \\
\hline hv30 & 2.83 & hv30 & 2.77 & hv30 & 2.84 \\
\hline hv50 & 3.16 & hv50 & 3.27 & hv50 & 3.26 \\
\hline \multicolumn{2}{|c|}{ Public industry } & \multicolumn{2}{|c|}{ Finance industry } & \multicolumn{2}{|c|}{ Energy industry } \\
\hline \multicolumn{2}{|c|}{ Optimal bandwidth } & \multicolumn{2}{|c|}{ Optimal bandwidth } & \multicolumn{2}{|c|}{ Optimal bandwidth } \\
\hline hv5 & 3.93 & hv5 & 3.87 & hv5 & 4.16 \\
\hline hv15 & 2.86 & hv15 & 2.19 & hv15 & 3.23 \\
\hline hv30 & 2.47 & hv30 & 2.53 & hv30 & 2.66 \\
\hline hv50 & 2.98 & hv50 & 2.86 & hv50 & 3.09 \\
\hline \multicolumn{2}{|c|}{ Consumption industry } & \multicolumn{2}{|c|}{ Information industry } & \multicolumn{2}{|c|}{ Pharmaceutical industry } \\
\hline \multicolumn{2}{|c|}{ Optimal bandwidth } & \multicolumn{2}{|c|}{ Optimal bandwidth } & \multicolumn{2}{|c|}{ Optimal bandwidth } \\
\hline hv5 & 3.80 & hv5 & 4.08 & hv5 & 3.80 \\
\hline hv15 & 3.05 & hv15 & 3.40 & hv15 & 3.20 \\
\hline hv30 & 2.46 & hv30 & 3.00 & hv30 & 2.84 \\
\hline hv50 & 2.86 & hv50 & 3.32 & hv50 & 3.08 \\
\hline
\end{tabular}

TABLE 3: RDD results for nine industries under the optimal bandwidths.

\begin{tabular}{|c|c|c|c|c|c|}
\hline \multicolumn{2}{|c|}{ Material industry } & \multicolumn{2}{|c|}{ Telecommunications industry } & \multicolumn{2}{|r|}{ Industry } \\
\hline \multicolumn{2}{|l|}{ Hv5 } & \multicolumn{2}{|r|}{ hv5 } & \multicolumn{2}{|r|}{ hv5 } \\
\hline Lwald(tri) & $0.369^{* * *}(0.044)$ & Lwald(tri) & $0.171^{* * *}(0.007)$ & Lwald(tri) & $0.305^{* * *}(0.024)$ \\
\hline Lwald(rec) & $0.360^{* * *}(0.060)$ & Lwald(rec) & $0.164^{* * *}(0.012)$ & Lwald(rec) & $0.289^{* * *}(0.040)$ \\
\hline Lwald' & $0.430^{* * *}(0.041)$ & Lwald' & $0.226^{* * *}(0.005)$ & Lwald' & $0.392(0.025)$ \\
\hline hv15 & & & hv15 & & hv15 \\
\hline Lwald(tri) & $0.164^{* * *}(0.026)$ & Lwald(tri) & $0.103^{* * *}(0.001)$ & Lwald(tri) & $0.177^{* * *}(0.010)$ \\
\hline Lwald(rec) & $0.163^{* * *}(0.037)$ & Lwald(rec) & $0.102^{* * *}(0.002)$ & Lwald(rec) & $0.174^{* * *}(0.017)$ \\
\hline Lwald' & $0.207^{* * *}(0.059)$ & Lwald' & $0.102(/)$ & Lwald' & $0.175(/)$ \\
\hline hv30 & & & hv30 & & hv30 \\
\hline Lwald(tri) & $0.087^{* * *}(0.008)$ & Lwald(tri) & $0.064^{* * *}(0.001)$ & Lwald(tri) & $0.083^{* * *}(0.002)$ \\
\hline Lwald(rec) & $0.084^{* * *}(0.014)$ & Lwald(rec) & $0.064^{* * *}(0.001)$ & Lwald(rec) & $0.083^{* * *}(0.003)$ \\
\hline Lwald' & $0.085(/)$ & Lwald' & $0.064(/)$ & Lwald' & $0.083(/)$ \\
\hline hv50 & & & hv50 & & hv50 \\
\hline Lwald(tri) & $0.066^{* * *}(0.010)$ & Lwald(tri) & $0.035^{* * *}(0.003)$ & Lwald(tri) & $0.060^{* * *}(0.006)$ \\
\hline Lwald(rec) & $0.060^{* * *}(0.009)$ & Lwald(rec) & $0.035^{* * *}(0.001)$ & Lwald(rec) & $0.059^{* * *}(0.002)$ \\
\hline Lwald' & $0.079^{* *}(0.033)$ & Lwald' & $0.056^{* * *}(0.016)$ & Lwald' & $0.083^{* * *}(0.023)$ \\
\hline Public ind & & & ance industry & & Energy industry \\
\hline hv5 & & & hv5 & & hv5 \\
\hline Lwald(tri) & $0.323^{* * *}(0.022)$ & Lwald(tri) & $0.203^{* * *}(0.012)$ & Lwald(tri) & $0.203^{* * *}(0.052)$ \\
\hline Lwald(rec) & $0.310^{* * *}(0.033)$ & Lwald(rec) & $0.196^{* * *}(0.022)$ & Lwald(rec) & $0.192^{* * *}(0.072)$ \\
\hline Lwald' & $0.391^{* * *}(0.040)$ & Lwald' & $0.267^{* * *}(0.046)$ & Lwald' & $0.241^{* * *}(0.043)$ \\
\hline hv15 & & & hv15 & & hv15 \\
\hline Lwald(tri) & $0.158^{* * *}(0.010)$ & Lwald(tri) & $0.105^{* * *}(0.010)$ & Lwald(tri) & $0.123^{* * *}(0.025)$ \\
\hline Lwald(rec) & $0.155^{* * *}(0.017)$ & Lwald(rec) & $0.102^{* * *}(0.017)$ & Lwald(rec) & $0.121^{* * *}(0.042)$ \\
\hline Lwald' & $0.156(/)$ & Lwald' & $0.103(/)$ & Lwald' & $0.141(0.042)$ \\
\hline hv30 & & & hv30 & & hv30 \\
\hline Lwald(tri) & $0.072^{* * *}(0.002)$ & Lwald(tri) & $0.052^{* * *}(/)$ & Lwald(tri) & $0.052^{* * *}(0.010)$ \\
\hline Lwald(rec) & $0.071(/)$ & Lwald(rec) & $0.050(/)$ & Lwald(rec) & $0.049^{* * *}(0.018)$ \\
\hline Lwald' & $0.072(/)$ & Lwald' & $0.052(/)$ & Lwald' & $0.050(/)$ \\
\hline hv50 & & & hv50 & & hv50 \\
\hline Lwald(tri) & $0.050^{* * *}(0.001)$ & Lwald(tri) & $0.032^{* * *}(0.0002)$ & Lwald(tri) & $0.036^{* * *}(0.007)$ \\
\hline Lwald(rec) & $0.050^{* * *}(0.002)$ & Lwald(rec) & $0.032^{* * *}(0.0004)$ & Lwald(rec) & $0.032^{* * *}(0.012)$ \\
\hline Lwald' & $0.050(/)$ & Lwald' & $0.032(/)$ & Lwald' & $0.038^{*}(0.021)$ \\
\hline Consumpti & & & nation industry & & Pharmaceutical industry \\
\hline
\end{tabular}


TABle 3: Continued.

\begin{tabular}{|c|c|c|c|c|c|}
\hline \multicolumn{2}{|c|}{ Material industry } & \multicolumn{2}{|c|}{ Telecommunications industry } & \multirow{2}{*}{\multicolumn{2}{|c|}{ Industry }} \\
\hline Hv5 & & & hv5 & & \\
\hline hv5 & & & hv5 & & hv5 \\
\hline Lwald(tri) & $0.279^{* * *}(0.009)$ & Lwald(tri) & $0.324^{* * *}(0.022)$ & Lwald(tri) & $0.440^{* * *}(0.025)$ \\
\hline Lwald(rec) & $0.295^{* * *}(0.014)$ & Lwald(rec) & $0.326^{* * *}(0.033)$ & Lwald(rec) & $0.475^{* * *}(0.004)$ \\
\hline $\begin{array}{l}\text { Lwald' } \\
\text { hv15 }\end{array}$ & $0.355^{* * *}(0.023)$ & Lwald' & $\begin{array}{l}0.351^{* * *}(0.036) \\
\text { hv15 }\end{array}$ & Lwald' & $\begin{array}{l}\quad 0.541^{* * *}(/) \\
\text { hv15 }\end{array}$ \\
\hline Lwald(tri) & $0.120^{* * *}(0.002)$ & Lwald(tri) & $0.169^{* * *}(0.016)$ & Lwald(tri) & $0.169^{* * *}(0.010)$ \\
\hline Lwald(rec) & $0.121^{* * *}(0.0004)$ & Lwald(rec) & $0.167^{* * *}(0.005)$ & Lwald(rec) & $0.172^{* * *}(0.004)$ \\
\hline $\begin{array}{l}\text { Lwald' } \\
\text { hv30 }\end{array}$ & $0.152^{* * *}(0.025)$ & Lwald' & $\begin{array}{l}0.231^{* * *} \\
\text { hv30 }\end{array}$ & Lwald' & $\begin{array}{l}0.225^{* * *}(0.041) \\
\text { hv30 }\end{array}$ \\
\hline Lwald(tri) & $0.068^{* * *}(0.0004)$ & Lwald(tri) & $0.102^{* * *}(0.0003)$ & Lwald(tri) & $0.099^{* * *}(0.001)$ \\
\hline Lwald(rec) & $0.067(/)$ & Lwald(rec) & $0.102^{* * *}(0.0004)$ & Lwald(rec) & $0.099^{* * *}(0.001)$ \\
\hline Lwald' & $0.068(/)$ & Lwald' & $0.102(/)$ & Lwald' & $0.099(/)$ \\
\hline hv50 & & & hv50 & & hv50 \\
\hline Lwald(tri) & $0.046^{* * *}(0.001)$ & Lwald(tri) & $0.064^{* * *}(0.011)$ & Lwald(tri) & $0.061^{* * *}(0.002)$ \\
\hline Lwald(rec) & $0.046^{* * *}(0.001)$ & Lwald(rec) & $0.055^{* * *}(0.001)$ & Lwald(rec) & $0.062^{* * *}(0.001)$ \\
\hline Lwald' & $0.046(/)$ & Lwald' & $0.080^{* *}(/)$ & Lwald' & $0.081^{* * *}(0.013)$ \\
\hline
\end{tabular}

Robust standard errors with estimated coefficients are in the brackets. ${ }^{* * *} p<0.01,{ }^{* *} p<0.05$, and ${ }^{*} p<0.1$.

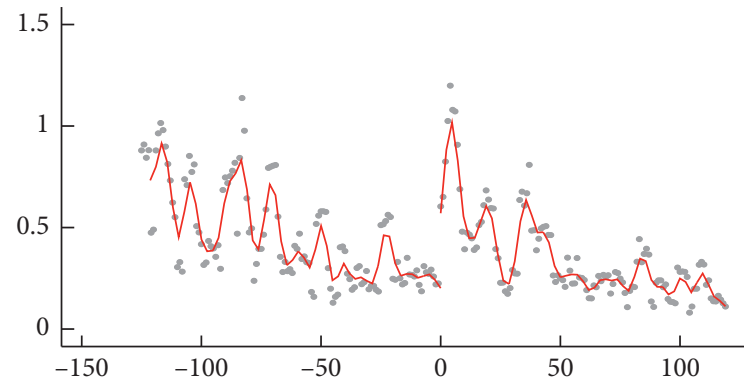

(a)

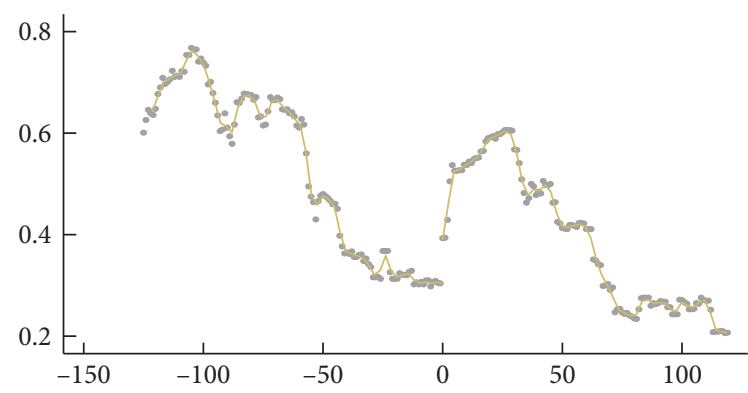

(c)

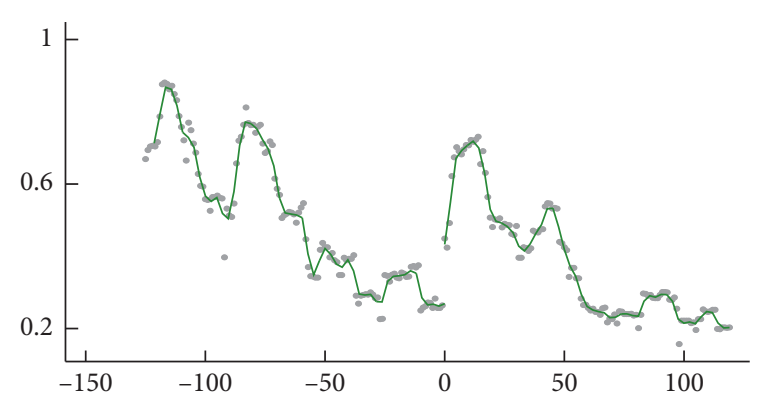

(b)

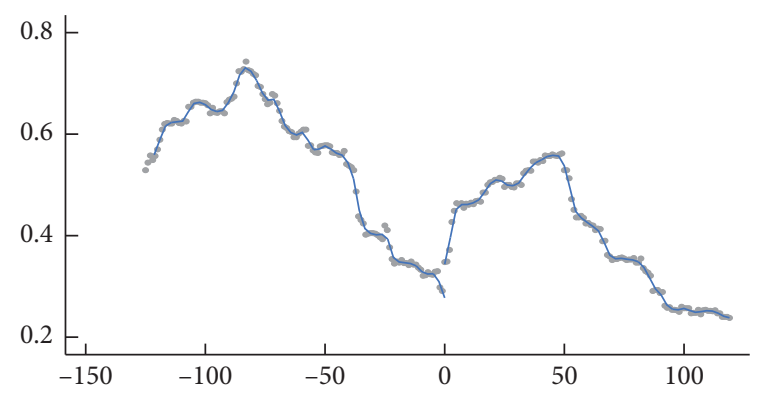

(d)

Figure 1: The RDD results of the material industry. (a) hv5, (b) hv15, (c) hv30, and (d) hv50.

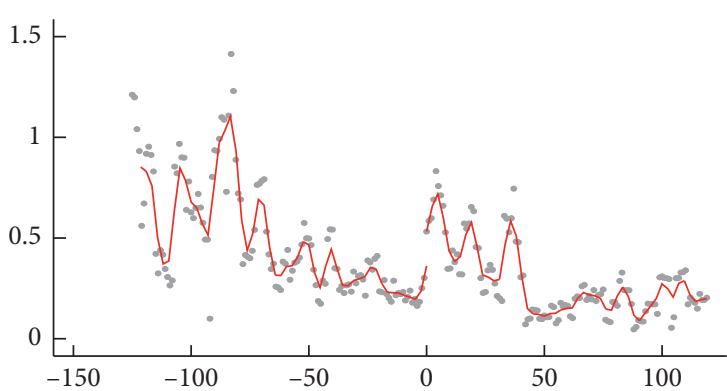

(a)

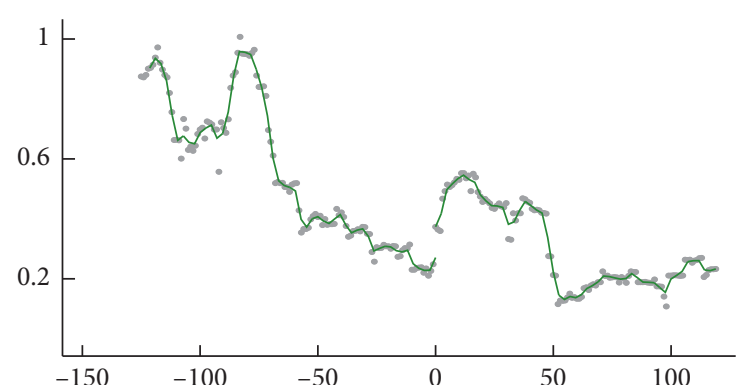

(b)

Figure 2: Continued. 


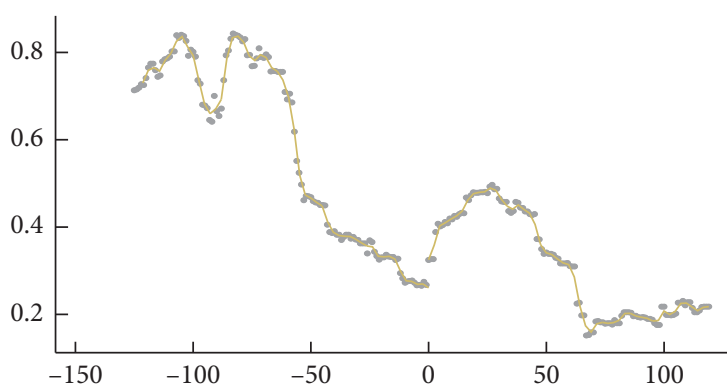

(c)

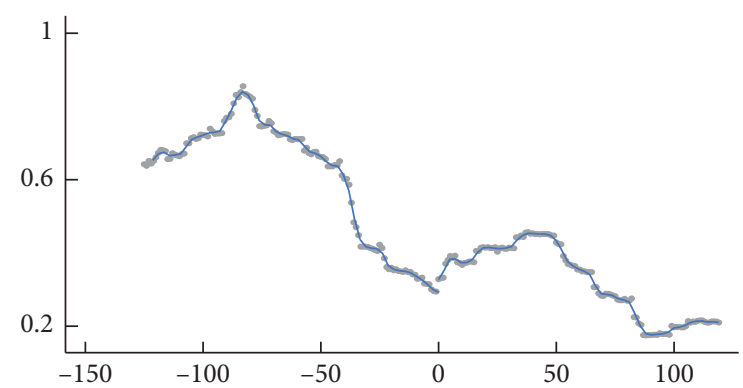

(d)

FIgURE 2: The RDD results of the telecommunications industry. (a) hv5, (b) hv15, (c) hv30, and (d) hv50.

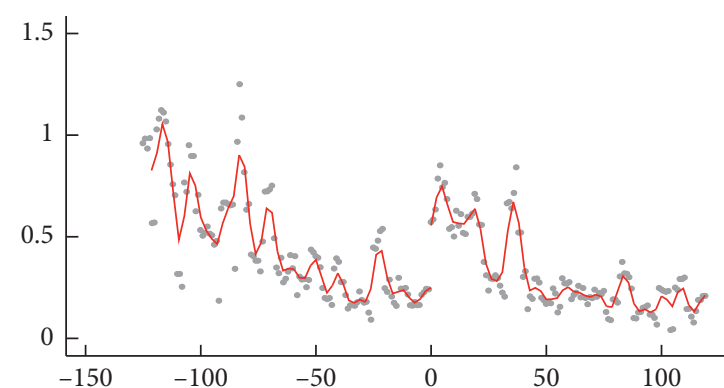

(a)

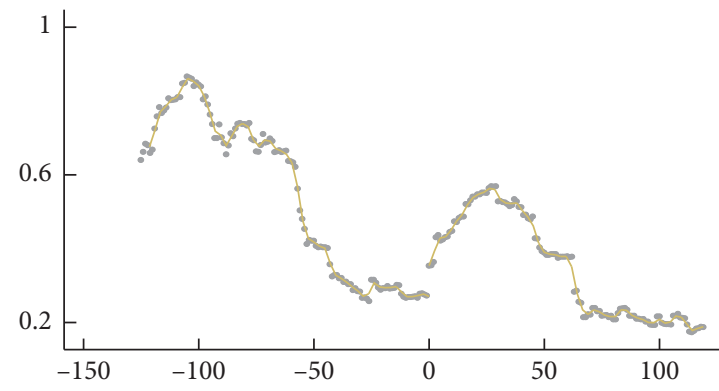

(c)

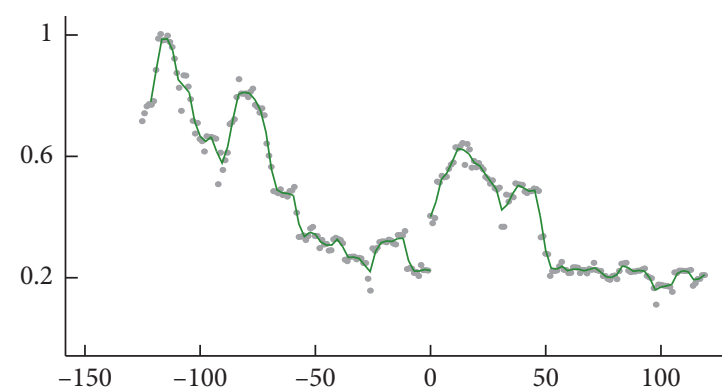

(b)

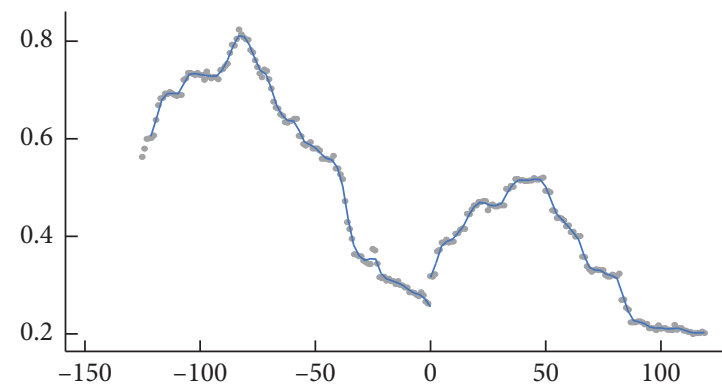

(d)

FIgURE 3: The RDD results of the industry. (a) hv5, (b) hv15, (c) hv30, and (d) hv50.

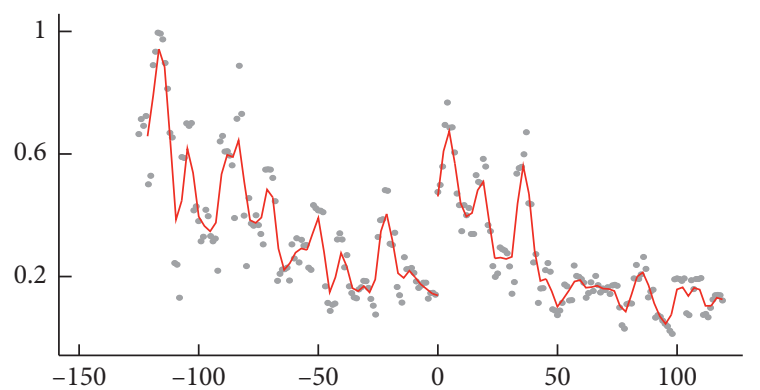

(a)

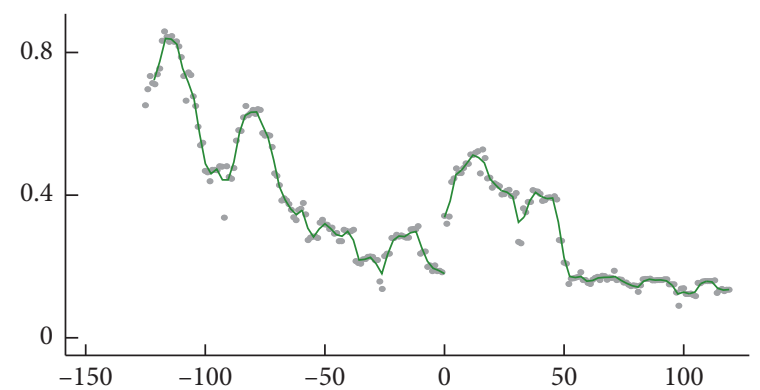

(b)

FIGURE 4: Continued. 


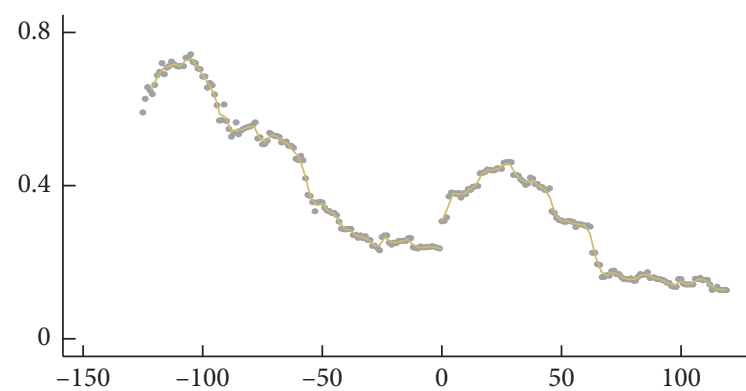

(c)

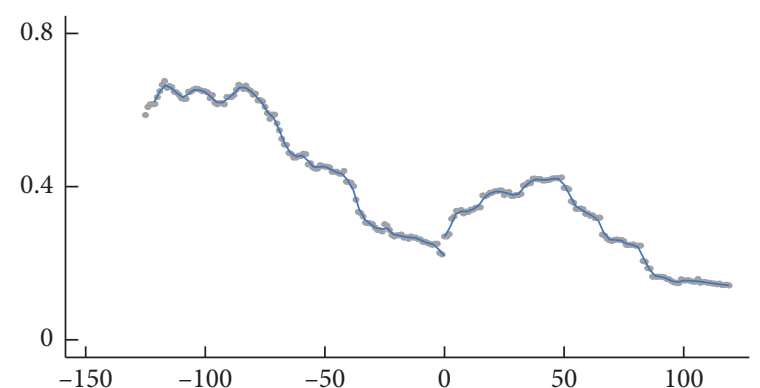

(d)

Figure 4: The RDD results of the public industry. (a) hv5, (b) hv15, (c) hv30, and (d) hv50.

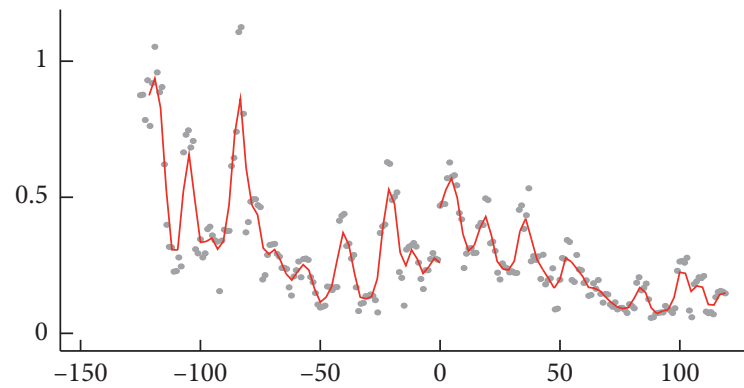

(a)

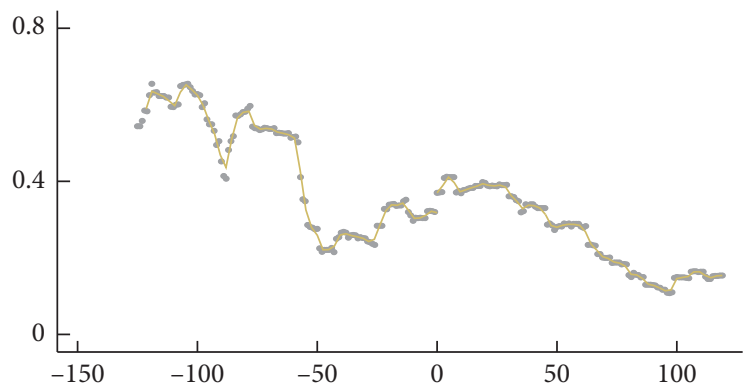

(c)

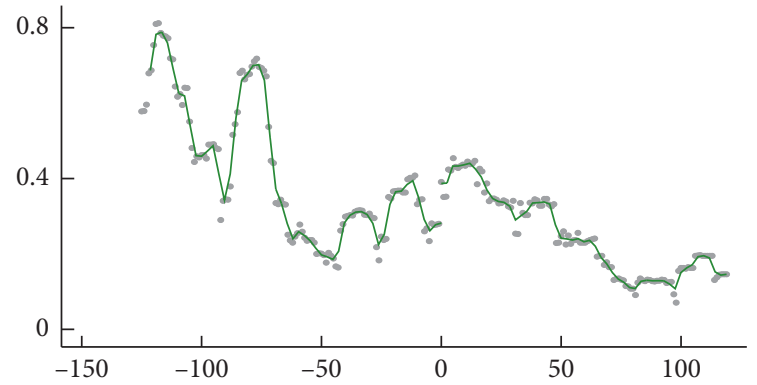

(b)

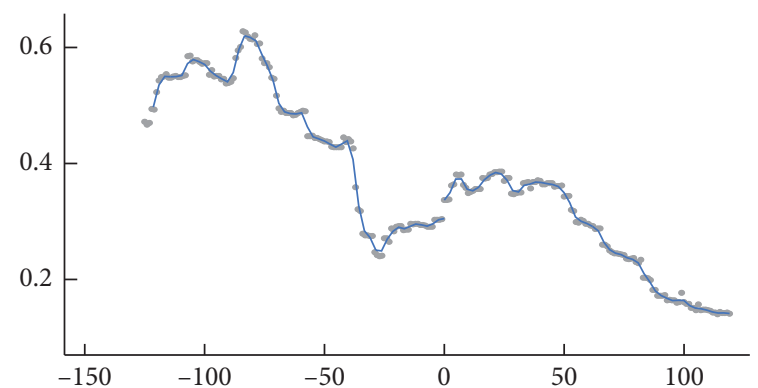

(d)

Figure 5: The RDD results of the finance industry. (a) hv5, (b) hv15, (c) hv30, and (d) hv50.

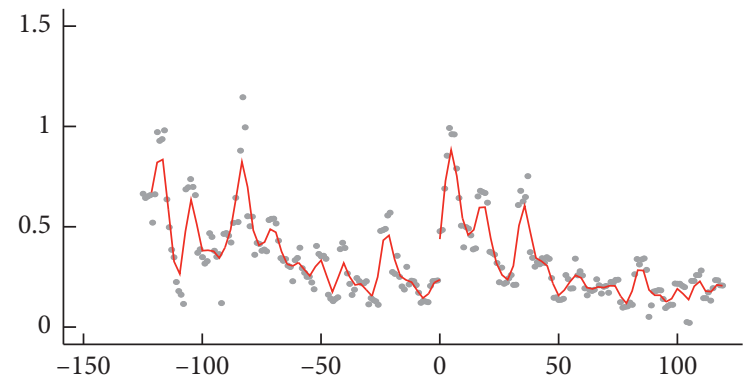

(a)

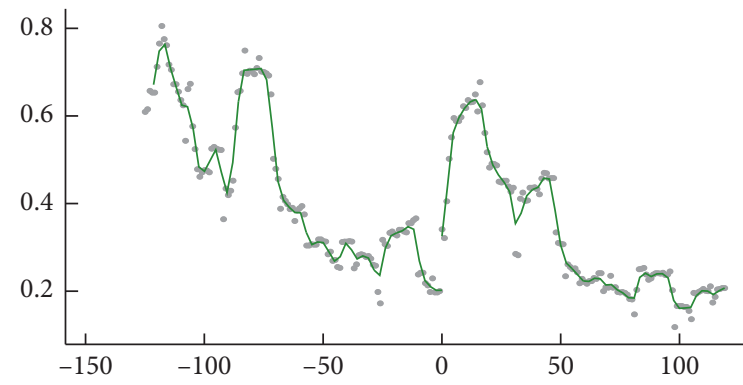

(b)

FIgUre 6: Continued. 


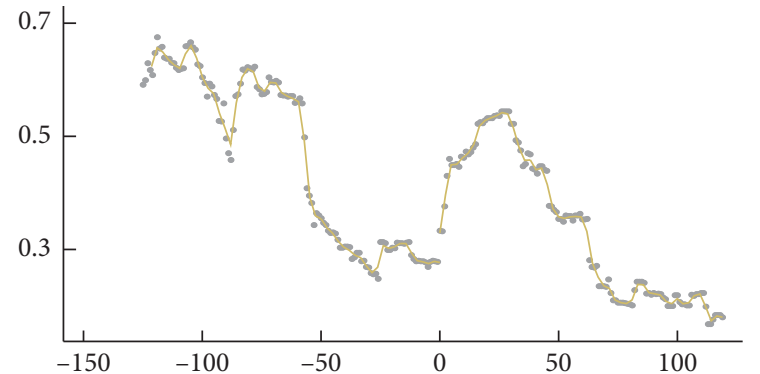

(c)

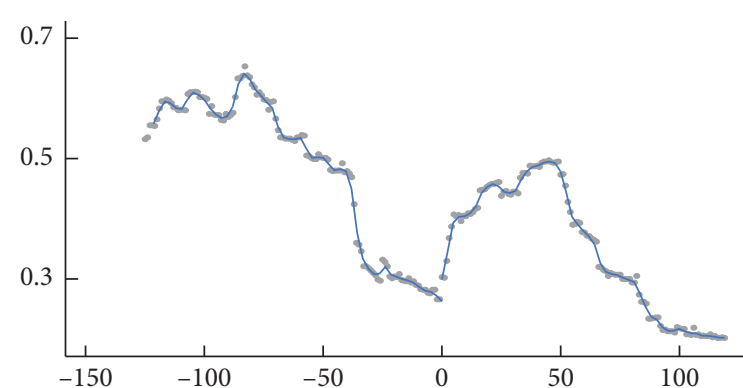

(d)

Figure 6: The RDD results of the energy industry. (a) hv5, (b) hv15, (c) hv30, and (d) hv50.

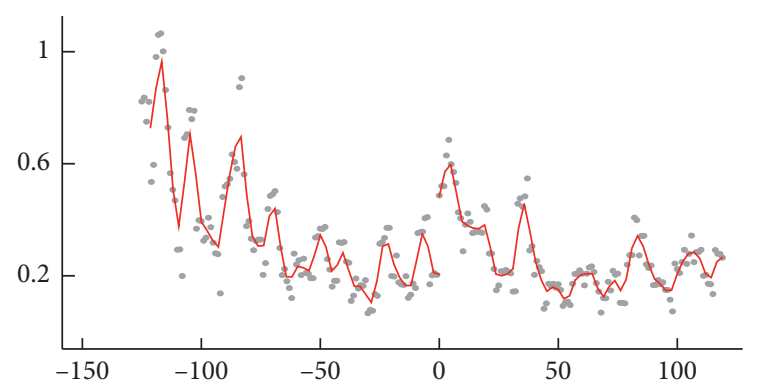

(a)

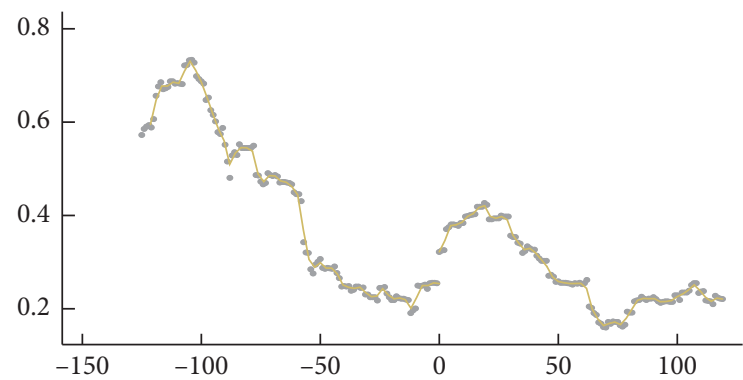

(c)

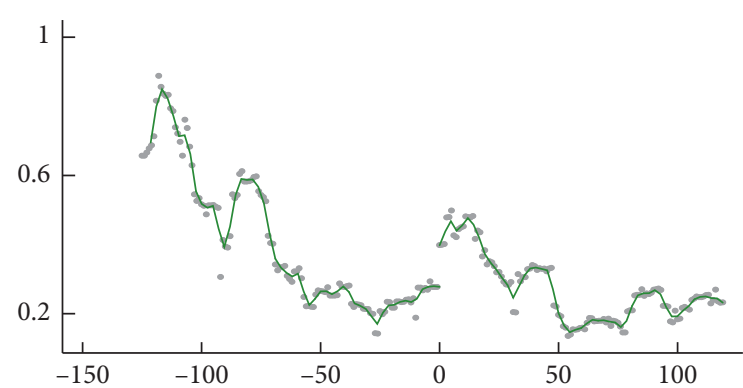

(b)

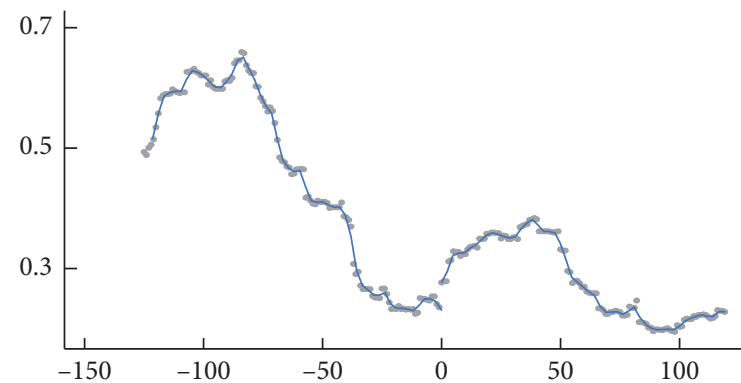

(d)

FIgURE 7: The RDD results of the consumption industry. (a) hv5, (b) hv15, (c) hv30, and (d) hv50.

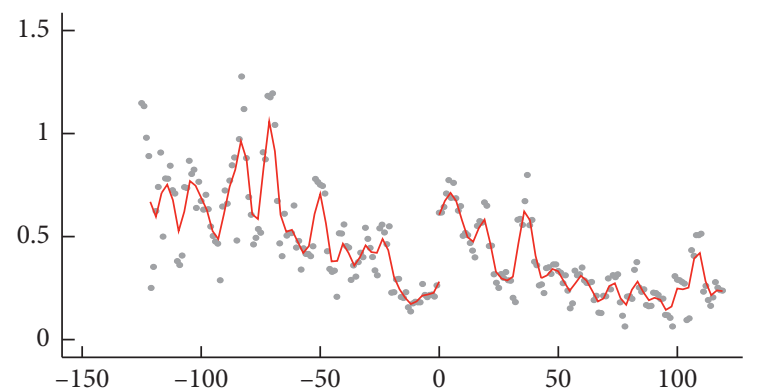

(a)

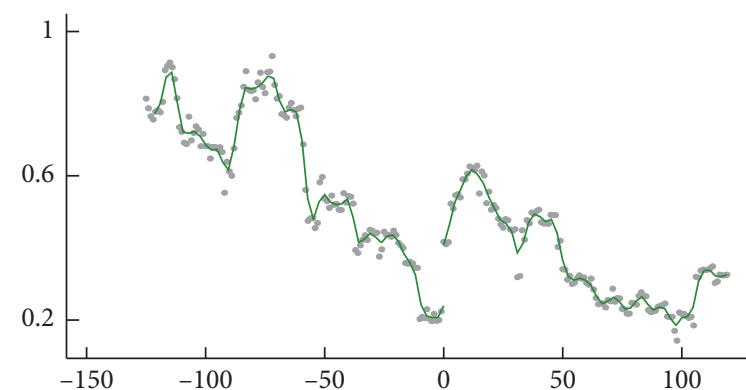

(b)

Figure 8: Continued. 


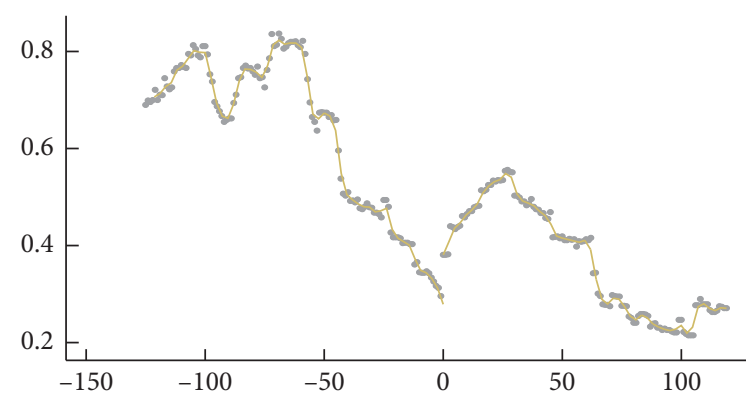

(c)

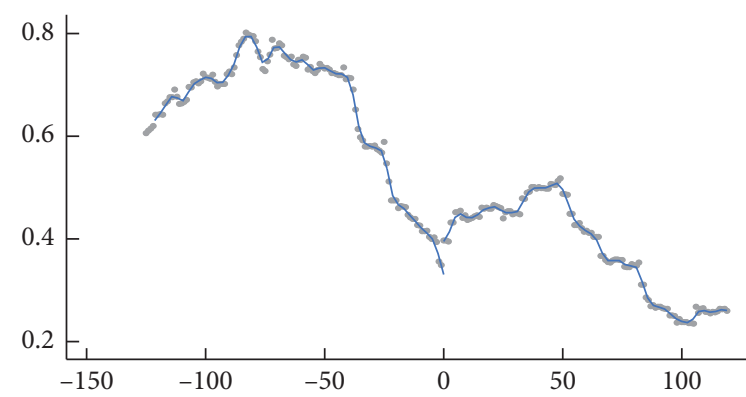

(d)

Figure 8: The RDD results of the information industry. (a) hv5, (b) hv15, (c) hv30, and (d) hv50.

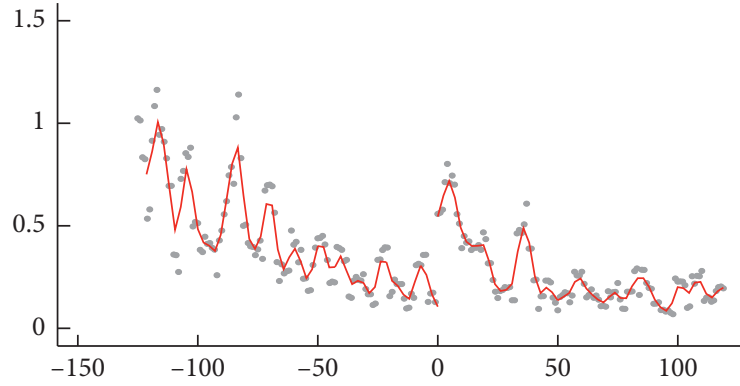

(a)

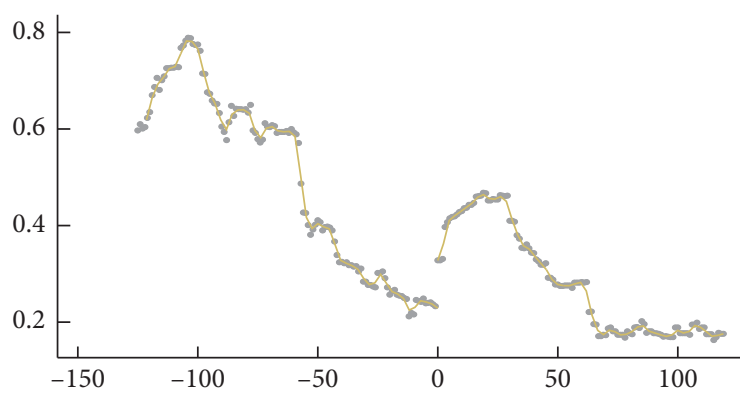

(c)

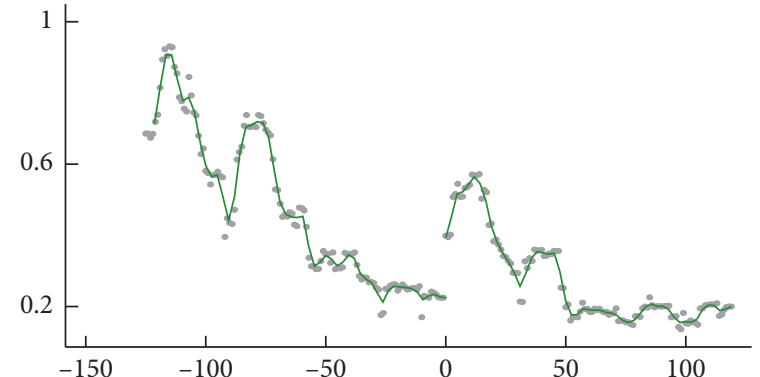

(b)

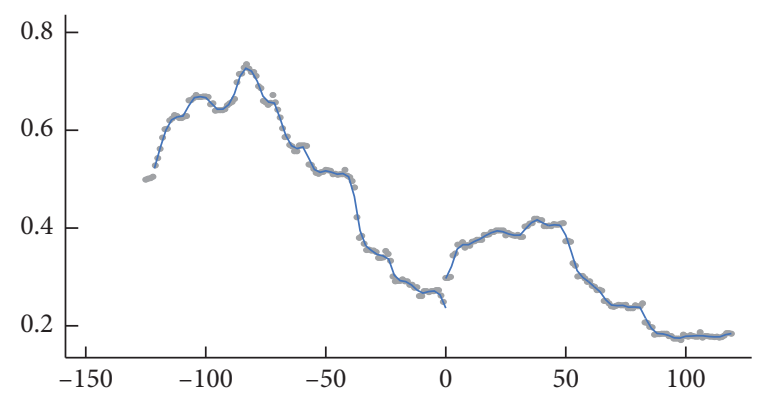

(d)

Figure 9: The RDD results of the pharmaceutical industry. (a) hv5, (b) hv15, (c) hv30, and (d) hv50.

TABLE 4: RDD results for multiple bandwidths.

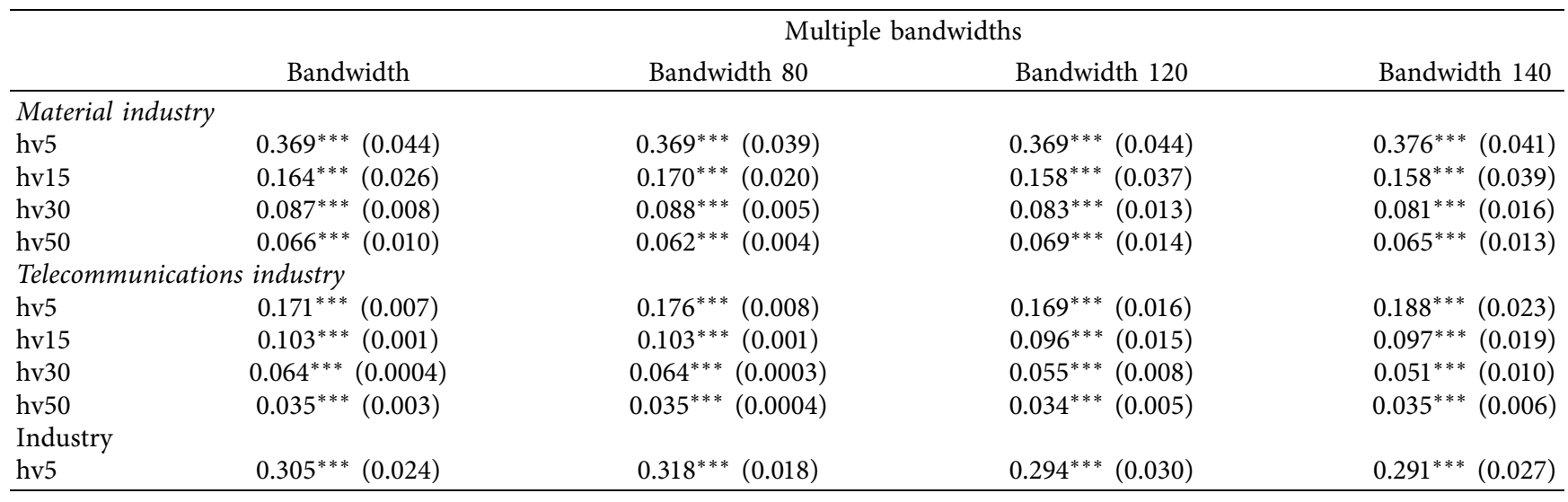


TABle 4: Continued.

\begin{tabular}{|c|c|c|c|c|}
\hline & \multicolumn{4}{|c|}{ Multiple bandwidths } \\
\hline & Bandwidth & Bandwidth 80 & Bandwidth 120 & Bandwidth 140 \\
\hline hv15 & $0.177^{* * *}(0.010)$ & $0.178^{* * *}(0.007)$ & $0.166^{* * *}(0.023)$ & $0.162^{* * *}(0.025)$ \\
\hline hv30 & $0.083^{* * *}(0.002)$ & $0.084^{* * *}(0.001)$ & $0.079^{* * *}(0.008)$ & $0.077^{* * *}(0.011)$ \\
\hline hv50 & $0.060^{* * *}(0.006)$ & $0.059^{* * *}(0.001)$ & $0.059^{* * *}(0.008)$ & $0.058^{* * *}(0.008)$ \\
\hline \multicolumn{5}{|c|}{ Public industry } \\
\hline hv5 & $0.323^{* * *}(0.022)$ & $0.332^{* * *}(0.012)$ & $0.310^{* * *}(0.025)$ & $0.318^{* * *}(0.022)$ \\
\hline hv15 & $0.158^{* * *}(0.010)$ & $0.159^{* * *}(0.007)$ & $0.148^{* * *}(0.019)$ & $0.143^{* * *}(0.021)$ \\
\hline hv30 & $0.072^{* * *}(0.002)$ & $0.071(/)$ & $0.072^{* * *}(0.002)$ & $0.068^{* * *}(0.007)$ \\
\hline hv50 & $0.050^{* * *}(0.001)$ & $0.051^{* * *}(0.001)$ & $0.056^{* * *}(0.009)$ & $0.055^{* * *}(0.008)$ \\
\hline \multicolumn{5}{|c|}{ Finance industry } \\
\hline hv5 & $0.203^{* * *}(0.012)$ & $0.204^{* * *}(0.005)$ & $0.189^{* * *}(0.017)$ & $0.178^{* * *}(0.019)$ \\
\hline hv15 & $0.105^{* * *}(0.010)$ & $0.106^{* * *}(0.007)$ & $0.097^{* * *}(0.019)$ & $0.094^{* * *}(0.021)$ \\
\hline hv30 & $0.052^{* * *}(/)$ & $0.052^{* * *}(/)$ & $0.052^{* * *}(0.001)$ & $0.049^{* * *}(0.004)$ \\
\hline hv50 & $0.032^{* * *}(0.0002)$ & $0 . .032^{* * *}(0.0002)$ & $0.031^{* * *}(0.003)$ & $0.030^{* * *}(0.004)$ \\
\hline \multicolumn{5}{|c|}{ Energy industry } \\
\hline hv5 & $0.203^{* * *} .(0.052)$ & $0.215^{* * *} .(0.047)$ & $0.192^{* * *} .(0.057)$ & $0.181^{* * *} .(0.051)$ \\
\hline hv15 & $0.123^{* * *}(0.025)$ & $0.129^{* * *}(0.022)$ & $0.118^{* * *}(0.033)$ & $0.121^{* * *}(0.034)$ \\
\hline hv30 & $0.052^{* * *}(0.010)$ & $0.054^{* * *}(0.005)$ & $0.049^{* * *}(0.011)$ & $0.047^{* * *}(0.015)$ \\
\hline hv50 & $0.036^{* * *}(0.007)$ & $0.035^{* * *}(0.006)$ & $0.038^{* * *}(0.011)$ & $0.037^{* * *}(0.011)$ \\
\hline \multicolumn{5}{|c|}{ Consumption industry } \\
\hline hv5 & $0.279^{* * *}(0.009)$ & $0.290^{* * *}(0.006)$ & $0.264^{* * *}(0.015)$ & $0.286^{* * *}(0.031)$ \\
\hline hv15 & $0.120^{* * *}(0.002)$ & $0.121^{* * *}(0.0002)$ & $0.115^{* * *}(0.010)$ & $0.114^{* * *}(0.011)$ \\
\hline hv30 & $0.068^{* * *}(0.0004)$ & $0.067(/)$ & $0.068^{* * *}(0.001)$ & $0.065^{* * *}(0.005)$ \\
\hline hv50 & $0.046^{* * *}(0.0005)$ & $0.046^{* * *}(0.0003)$ & $0.047^{* * *}(0.004)$ & $0.047^{* * *}(0.005)$ \\
\hline \multicolumn{5}{|c|}{ Information industry } \\
\hline hv5 & $0.324^{* * *}(0.022)$ & $0.315^{* * *}(0.023)$ & $0.330^{* * *}(0.028)$ & $0.340^{* * *}(0.027)$ \\
\hline hv15 & $0.169^{* * *}(0.016)$ & $0.168^{* * *}(0.003)$ & $0.170^{* * *}(0.018)$ & $0.176^{* * *}(0.022)$ \\
\hline hv30 & $0.102^{* * *}(0.0003)$ & $0.102^{* * *}(0.0002)$ & $0.092^{* * *}(0.009)$ & $0.088^{* * *}(0.009)$ \\
\hline hv50 & $0.064^{* * *}(0.011)$ & $0.055^{* * *}(0.0004)$ & $0.067^{* * *}(0.011)$ & $0.066^{* * *}(0.009)$ \\
\hline \multicolumn{5}{|c|}{ Pharmaceutical industry } \\
\hline hv5 & $0.440^{* * *}(0.025)$ & $0.470^{* * *}(0.008)$ & $0.408^{* * *}(0.036)$ & $0.418^{* * *}(0.039)$ \\
\hline hv15 & $0.169^{* * *}(0.010)$ & $0.173^{* * *}(0.002)$ & $0.163^{* * *}(0.017)$ & $\left.0.161^{* * *} 0.018\right)$ \\
\hline hv30 & $0.099^{* * *}(0.001)$ & $0.099^{* * *}(0.0004)$ & $0.094^{* * *}(0.008)$ & $0.092^{* * *}(0.010)$ \\
\hline hv50 & $0.061^{* * *}(0.002)$ & $0.062^{* * *}(0.0004)$ & $0.057^{* * *}(0.006)$ & $0.053^{* * *}(0.007)$ \\
\hline
\end{tabular}

Table 5: The jump test results of the conditional density function at the breakpoint.

\begin{tabular}{|c|c|c|c|c|c|c|c|c|c|c|c|}
\hline \multirow{2}{*}{\multicolumn{4}{|c|}{$\begin{array}{l}\text { Material industry } \\
\text { hv5 }\end{array}$}} & \multirow{2}{*}{\multicolumn{4}{|c|}{$\begin{array}{l}\text { Telecommunications industry } \\
\text { hv5 }\end{array}$}} & \multirow{2}{*}{\multicolumn{4}{|c|}{$\begin{array}{l}\text { Industry } \\
\text { hv5 }\end{array}$}} \\
\hline & & & & & & & & & & & \\
\hline DOW & $\begin{array}{l}\text { Coef. } \\
0.007\end{array}$ & $\begin{array}{c}\text { Std. error } \\
0.010\end{array}$ & $\begin{array}{l}\text { Prob. } \\
0.453\end{array}$ & DOW & $\begin{array}{l}\text { Coef. } \\
0.009\end{array}$ & $\begin{array}{l}\text { Std. error } \\
0.009\end{array}$ & $\begin{array}{l}\text { Prob. } \\
0.337\end{array}$ & DOW & $\begin{array}{l}\text { Coef. } \\
0.009\end{array}$ & $\begin{array}{l}\text { Std. error } \\
0.009\end{array}$ & $\begin{array}{l}\text { Prob. } \\
0.348\end{array}$ \\
\hline CFETS & 0.002 & 0.002 & 0.214 & CFETS & 0.002 & 0.002 & 0.369 & CFETS & 0.002 & 0.002 & 0.351 \\
\hline \multirow[t]{2}{*}{ hv15 } & & & & \multicolumn{4}{|c|}{ hv15 } & \multicolumn{4}{|c|}{ hv15 } \\
\hline & Coef. & Std. error & Prob. & & Coef. & Std. error & Prob. & & Coef. & Std. error & Prob. \\
\hline DOW & 0.005 & 0.009 & 0.592 & DOW & -0.001 & 0.008 & 0.871 & DOW & -0.001 & 0.008 & 0.860 \\
\hline CFETS & 0.002 & 0.002 & 0.262 & CFETS & 0.003 & 0.002 & 0.240 & CFETS & 0.003 & 0.002 & 0.225 \\
\hline \multirow[t]{2}{*}{ hv30 } & & & & \multicolumn{4}{|c|}{ hv30 } & \multicolumn{4}{|c|}{ hv30 } \\
\hline & Coef. & Std. error & Prob. & & Coef. & Std. error & Prob. & & Coef. & Std. error & Prob. \\
\hline DOW & -0.001 & 0.008 & 0.848 & DOW & -0.002 & 0.008 & 0.836 & DOW & -0.001 & 0.008 & 0.849 \\
\hline CFETS & 0.003 & 0.002 & 0.209 & CFETS & 0.003 & 0.002 & 0.194 & CFETS & 0.003 & 0.002 & 0.210 \\
\hline \multirow[t]{2}{*}{ hv50 } & & & & \multicolumn{4}{|c|}{ hv50 } & \multicolumn{4}{|c|}{ hv50 } \\
\hline & Coef. & Std. error & Prob. & & Coef. & Std. error & Prob. & & Coef. & Std. error & Prob. \\
\hline DOW & 0.004 & 0.008 & 0.650 & DOW & 0.005 & 0.009 & 0.553 & DOW & 0.005 & 0.009 & 0.560 \\
\hline CFETS & 0.002 & 0.002 & 0.229 & CFETS & 0.002 & 0.002 & 0.288 & CFETS & 0.002 & 0.002 & 0.283 \\
\hline \multicolumn{4}{|c|}{$\begin{array}{l}\text { Public industry } \\
\text { hv5 }\end{array}$} & \multicolumn{4}{|c|}{$\begin{array}{c}\text { Finance industry } \\
\text { hv5 }\end{array}$} & \multicolumn{4}{|c|}{$\begin{array}{l}\text { Energy industry } \\
\text { hv5 }\end{array}$} \\
\hline & Coef. & Std. error & Prob. & & Coef. & Std. error & Prob. & & Coef. & Std. error & Prob. \\
\hline
\end{tabular}


TABLE 5: Continued.

\begin{tabular}{|c|c|c|c|c|c|c|c|c|c|c|c|}
\hline \multirow{2}{*}{\multicolumn{4}{|c|}{$\begin{array}{l}\text { Material industry } \\
\text { hv5 }\end{array}$}} & \multicolumn{4}{|c|}{ Telecommunications industry } & \multicolumn{4}{|c|}{ Industry } \\
\hline & & & & \multicolumn{4}{|c|}{ hv5 } & \multicolumn{4}{|c|}{ hv5 } \\
\hline DOW & 0.009 & 0.011 & 0.391 & DOW & 0.009 & 0.011 & 0.397 & DOW & 0.008 & 0.009 & 0.408 \\
\hline CFETS & 0.001 & 0.002 & 0.449 & CFETS & 0.002 & 0.002 & 0.440 & CFETS & 0.002 & 0.002 & 0.264 \\
\hline \multicolumn{4}{|l|}{ hv15 } & \multicolumn{4}{|c|}{ hv15 } & \multicolumn{4}{|c|}{ hv15 } \\
\hline & Coef. & Std. error & Prob. & & Coef. & Std. error & Prob. & & Coef. & Std. error & Prob. \\
\hline DOW & -0.001 & 0.008 & 0.854 & DOW & -0.001 & 0.008 & 0.862 & DOW & 0.005 & 0.009 & 0.586 \\
\hline CFETS & 0.003 & 0.002 & 0.216 & CFETS & 0.003 & 0.002 & 0.227 & CFETS & 0.002 & 0.002 & 0.266 \\
\hline \multicolumn{4}{|l|}{ hv30 } & \multicolumn{4}{|c|}{ hv30 } & \multicolumn{4}{|c|}{ hv30 } \\
\hline & Coef. & Std. error & Prob. & & Coef. & Std. error & Prob. & & Coef. & Std. error & Prob. \\
\hline DOW & -0.002 & 0.006 & 0.750 & DOW & -0.002 & 0.007 & 0.772 & DOW & -0.002 & 0.007 & 0.812 \\
\hline CFETS & 0.003 & 0.002 & 0.108 & CFETS & 0.003 & 0.002 & 0.127 & CFETS & 0.003 & 0.002 & 0.167 \\
\hline \multirow[t]{2}{*}{ hv50 } & & & & \multicolumn{4}{|c|}{ hv50 } & \multicolumn{4}{|c|}{ hv50 } \\
\hline & Coef. & Std. error & Prob. & & Coef. & Std. error & Prob. & & Coef. & Std. error & Prob. \\
\hline DOW & -0.001 & 0.008 & 0.872 & DOW & -0.001 & 0.008 & 0.852 & DOW & 0.002 & 0.008 & 0.765 \\
\hline CFETS & 0.003 & 0.002 & 0.241 & CFETS & 0.003 & 0.002 & 0.215 & CFETS & 0.002 & 0.002 & 0.176 \\
\hline \multicolumn{4}{|c|}{$\begin{array}{l}\text { Consumption industry } \\
\text { hv5 }\end{array}$} & \multicolumn{4}{|c|}{$\begin{array}{l}\text { Information industry } \\
\text { hv5 }\end{array}$} & \multicolumn{4}{|c|}{$\begin{array}{c}\text { Pharmaceutical industry } \\
\text { hv5 }\end{array}$} \\
\hline & Coef. & Std. error & Prob. & & Coef. & Std. error & Prob. & & Coef. & Std. error & Prob. \\
\hline DOW & 0.009 & 0.011 & 0.405 & DOW & 0.008 & 0.009 & 0.372 & DOW & 0.009 & 0.011 & 0.405 \\
\hline \multirow{3}{*}{ hv15 } & 0.002 & 0.002 & 0.429 & CFETS & 0.002 & 0.002 & 0.313 & CFETS & 0.002 & 0.002 & 0.429 \\
\hline & & & & \multicolumn{4}{|c|}{ hv15 } & \multicolumn{4}{|c|}{ hv15 } \\
\hline & Coef. & Std. error & Prob. & & Coef. & Std. error & Prob. & & Coef. & Std. error & Prob. \\
\hline DOW & 0.001 & 0.007 & 0.897 & DOW & 0.007 & 0.010 & 0.489 & DOW & 0.005 & 0.009 & 0.607 \\
\hline CFETS & 0.002 & 0.002 & 0.135 & CFETS & 0.002 & 0.002 & 0.338 & CFETS & 0.002 & 0.002 & 0.253 \\
\hline hv30 & & & & \multicolumn{4}{|c|}{ hv30 } & \multicolumn{4}{|c|}{ hv30 } \\
\hline & Coef. & Std. error & Prob. & & Coef. & Std. error & Prob. & & Coef. & Std. error & Prob. \\
\hline DOW & -0.002 & 0.006 & 0.742 & DOW & -0.001 & 0.008 & 0.873 & DOW & -0.002 & 0.008 & 0.850 \\
\hline CFETS & 0.003 & 0.002 & 0.102 & CFETS & 0.003 & 0.002 & 0.243 & CFETS & 0.003 & 0.002 & 0.212 \\
\hline \multirow[t]{2}{*}{ hv50 } & & & & \multicolumn{4}{|c|}{ hv50 } & \multicolumn{4}{|c|}{ hv50 } \\
\hline & Coef. & Std. error & Prob. & & Coef. & Std. error & Prob. & & Coef. & Std. error & Prob. \\
\hline DOW & -0.001 & 0.008 & 0.853 & DOW & 0.006 & 0.009 & 0.522 & DOW & 0.002 & 0.007 & 0.783 \\
\hline CFETS & 0.003 & 0.002 & 0.216 & CFETS & 0.002 & 0.002 & 0.311 & CFETS & 0.002 & 0.002 & 0.170 \\
\hline
\end{tabular}

Besides, it can be found from Table 3 that the effect of the circuit breaker mechanism on the public industry and consumer industry performs at a moderate level, and the mechanism has one or more extreme effects on volatilities in the other seven industries. Thus, we can pilot from the public and consumer industry and gradually expand to other industries in the improved circuit breaker mechanism or other similar policy to reduce the risk of policy implementation in the future.

4.2. Robustness and Effectiveness Test of Empirical Results. In order to ensure the reliability of the empirical results, the RDD method needs a series of checks. In this section, three methods will be used to test the robustness of the estimated results, which includes changing the bandwidth, selecting different kernel functions, and adding and removing covariates. Then, the validity of the empirical results is tested by observing whether there is a jump of covariates at the breakpoint.

Table 4 reports the estimation results of the RDD model under different bandwidths. The optimal bandwidth is used in the second column of Table 4, and other bandwidths near the optimal bandwidth are used in the third, fourth, and fifth columns, respectively. The results show that the coefficients are all positive and the results obtained by using different bandwidths are very consistent. For example, the coefficients of hv5 in the material industry are $0.369,0.369,0.369$, and 0.376 under 0.8 times, 1 time, 1.2 times, and 1.4 times of optimal bandwidth, respectively. The change of these values can be almost ignored with the change of bandwidth, indicating that the estimated value is less dependent on the bandwidth. Therefore, the change of bandwidth has little impact on the result, which reflects the robustness of the results from one aspect.

The second row in Table 3 represents the estimated results of the rectangular core. It can be seen from Table 3 that, under the rectangle core, after the implementation of the circuit breaker mechanism, the effect of different kernel functions on the estimated results is very small that it is almost negligible. For example, for the material industry, the coefficient of hv5 changes by 0.009 , the coefficient of hv15 changes by 0.001 , the coefficient of hv30 changes by 0.003 , and the coefficient of hv50 changes by 0.006 , which indicates the robustness of the estimated results in this paper from one aspect.

The third row in Table 3 shows the estimation results of the triangle kernel with covariates. From Table 3, we can see that the addition of covariates has no significant impact on the results of RDD estimation. For example, under the 
triangle core, after the addition of covariates, the coefficient of hv5 at material industry changes about 0.061 , hv15 changes about 0.043 , hv30 changes about 0.002 , and hv50 changes about 0.013 . This shows the robustness of the estimation results from one aspect.

The way to verify the effectiveness of RDD estimates is to test whether the covariates are continuous at the breakpoint [29]. In Table 5, we examined whether there is a jump in the conditional density function of the covariates at the breakpoint. We can see that all estimation results of DOW and CFETS are not significant, which indicates that the conditional density function of the covariates is continuous at the breakpoint. In conclusion, DOW and CFETS have no significant effect on the formation of the breakpoint, which further proves the effectiveness of the regression results in this paper.

\section{Conclusions}

In this paper, we use the RDD method to study the policy effect of the circuit breaker mechanism on the volatility from the perspective of a single industry and provide some suggestions for the further circuit breaker mechanism in China in the future. Based on the study of this paper, we have derived the following conclusions: (1) there is an obvious causal relationship between the circuit breaker mechanism and the fluctuation of the CSI 300 industry. The implementation of the mechanism has led to an obvious breakpoint on nine industry indexes, and the volatility of all nine industries has increased significantly at the breakpoints. (2) The effect of the circuit breaker mechanism on different industries is different. The effect on the public and consumer industry is, especially, moderate among the nine industries.

Based on the above conclusion, we propose the following suggestions: (1) before implementing the circuit breaker mechanism, relevant institutions should conduct adequate market research and consider some emergency measures to prevent adverse consequences after the implementation of the policy. (2) It could be a good way to conduct a pilot test on the public and consumer industry and then gradually generalize to other industries and the whole market, which can avoid the huge loss caused by direct implementation in the whole CSI 300 index.

It should be pointed out that, due to the fact that the circuit breaker mechanism was only applied in four days and the availability of data, we only studied the causal relationship between the implementation of this mechanism and the volatility of CSI 300 nine industries but failed to conduct further study of the correlation.

\section{Data Availability}

The data used to support the findings of this empirical study are included within the supplementary information files.

\section{Conflicts of Interest}

The authors declare no conflicts of interest.

\section{Acknowledgments}

This work was supported by the Natural Science Foundation of China under Grants (72071176 and 71840001); Social Science Youth Foundation of Ministry of Education of China under Grant (18YJC790118), and Applied Basic Research Programs of Science and Technology Commission of Yunnan Province under Grant (2017FB102).

\section{Supplementary Materials}

The data used to support the findings of this empirical study are included within the supplementary information files. (Supplementary Materials)

\section{References}

[1] N. Apergis, "The role of circuit breakers in the oil futures market," Journal of Economics and Finance, vol. 4, no. 10, pp. 1-16, 2016.

[2] M. A. Goldstein, "Circuit breakers, trading collars, and volatility transmission across markets : Evidence from NYSE rule 80," Financial Review, vol. 50, no. 3, pp. 459-479, 2015.

[3] B. C. N. Greenwald and J. C. Stein, "Transactional risk, market crashes, and the role of circuit breakers," Journal of Business, vol. 64, no. 4, pp. 443-462, 1991.

[4] R. Bildik and S. Elekdag, "Effects of price limits on volatility: evidence from the Istanbul stock exchange," Emerging Markets Finance and Trade, vol. 40, no. 1, pp. 5-34, 2004.

[5] Y. L. Wan, W. J. Xie, G. F. Gu et al., "Statistical properties and pre-hit dynamics of price limit hits in the Chinese stock markets," PLoS One, vol. 10, no. 4, Article ID e0120312, 2015.

[6] T. Wu, Y. Wang, and M. X. Li, "Post-hit dynamics of price limit hits in the Chinese stock markets," Physica A: Statistical Mechanics and its Applications, vol. 465, no. 1, pp. 464-471, 2017.

[7] K. Q. Hou, X. Li, and W. Zhong, "Price limits and asymmetry of price dynamics - high frequency evidence from the Chinese stock market," Emerging Markets Finance and Trade, vol. 56, no. 7, pp. 1447-1461, 2020.

[8] A. Ascioglu, M. O. Karahan, and N. Yilmaz, "Price discovery between the New York stock exchange and istanbul stock exchange," Emerging Markets Finance \& Trade, vol. 51, no. 1, pp. 247-258, 2015.

[9] S. H. Chan, K. A. Kim, and S. G. Rhee, "Price limit performance: evidence from transactions data and the limit order book," Journal of Empirical Finance, vol. 12, no. 2, pp. 269290, 2005.

[10] C. H. Chang and S. L. Hsieh, "Is the daily price limit of the Taiwan stock exchange effective? Fundamentals of listed stocks and investors' perception of a fair price," Asia-Pacific Journal of Financial Studies, vol. 37, no. 4, pp. 675-726, 2008.

[11] L. F. Ackert, B. Church, and N. Jayaraman, "An experimental study of circuit breakers: the effects of mandated market closures and temporary halts on market behavior," Journal of Financial Markets, vol. 4, no. 2, pp. 185-208, 2001.

[12] W. G. Christie, S. A. Corwin, and J. H. Harris, "Nasdaq trading halts: the impact of market mechanisms on prices, trading activity, and execution costs," Journal of Finance, vol. 57, no. 3, pp. 1443-1478, 2002.

[13] Y. FJ. Zhang, L. N. Feng, X. Jin, D. H. Shen, X. Xiong, and W. Zhang, "Internet information arrival and volatility of SME 
PRICE INDEX," Physica A: Statistical Mechanics and its Applications, vol. 399, no. 8, pp. 70-74, 2014.

[14] L. N. Switzer and H. Yue, "Effects of the short sale circuit breaker on the stock market," Journal of International Financial Management \& Accounting, vol. 30, 2019.

[15] X. Zhang, J. Ping, T. Zhu, Y. Li, and X. Xiong, "Are price limits effective? An examination of an artificial stock market," PLoS One, vol. 11, no. 8, Article ID e0160406, 2016.

[16] Z. G. Li, K. Q. Hou, and C. Zhang, "The impacts of circuit breakers on China's stock market," Pacific-Basin Finance Journal, 2020.

[17] M. Khodavandloo, The Effects of Price Limits on Bursa Malaysia during 2007-2008 Crisis, Lap Lambert Academic Publishing, no. 3, pp. 4-92, Saarbrücken, Germany, 2012.

[18] C. Kearney and K. Daly, "The causes of stock market volatility in Australia," Applied Financial Economics, vol. 8, no. 6, pp. 597-605, 1998.

[19] V. Errunza and K. Hogan, "Macroeconomic determinants of European stock market volatility," European Financial Management, vol. 4, no. 3, pp. 361-377, 1998.

[20] M. H. Liu, D. Margaritis, and A. Tourani-Rad, "Monetary policy transparency and pass-through of retail interest rates," Journal of Banking and Finance, vol. 32, no. 4, pp. 0-511, 2008.

[21] N. D. Richards, J. Simpson, and J. Evans, "The interaction between exchange rates and stock prices: an Australian context," International Journal of Economics and Finance, vol. 1, no. 1, pp. 3-23, 2009.

[22] D. Muktadir-Al-Mukit, "The effects of interest rates volatility on stock returns: evidence from Bangladesh," Global Business and Management Research: An International Journal, vol. 3, no. 3, pp. 269-279, 2013.

[23] E. Girardin and R. Joyeux, "Macro fundamentals as a source of stock market volatility in China: a GARCH-MIDAS approach," Economic Modelling, vol. 34, pp. 59-68, 2013.

[24] J. Y. Campbell and T. Vuolteenaho, "Inflation illusion and stock prices," American Economic Review, vol. 94, no. 2, pp. 19-23, 2004.

[25] L. A. Gallagher and M. P. Taylor, "The stock return-inflation puzzle revisited," Economics Letters, vol. 75, no. 2, pp. 147156, 2002.

[26] G. W. Imbens and T. Lemieux, "Regression discontinuity designs: a guide to practice," Journal of Econometrics, vol. 142, no. 2, pp. 615-635, 2008.

[27] D. L. Thistlethwaite and D. T. Campbell, "Regression-discontinuity analysis: an alternative to the ex post facto experiment," Journal of Educational Psychology, vol. 51, no. 6, pp. 309-317, 1960.

[28] P. H. Egger and G. Wamser, "The impact of controlled foreign company legislation on real investments abroad. A multidimensional regression discontinuity design," Journal of Public Economics, vol. 129, pp. 77-91, 2015.

[29] D. Lee and T. Lemieux, "Regression discontinuity designs in economics," Journal of Economic Literature, vol. 48, no. 2, pp. 281-355, 2010.

[30] J. P. Papay, J. B. Willett, and R. J. Murnane, "Extending the regression-discontinuity approach to multiple assignment variables," Journal of Econometrics, vol. 161, no. 2, pp. 203207, 2011.

[31] S. O. Becker, P. H. Egger, and M. Von Ehrlich, “Absorptive capacity and the growth and investment effects of regional transfers: a regression discontinuity design with heterogeneous treatment effects," American Economic Journal: Economic Policy, vol. 5, no. 4, pp. 29-77, 2013.
[32] D. Ruppert and M. P. Wand, "Multivariate locally weighted least squares regression," Annals of Statistics, vol. 22, no. 3, pp. 1346-1370, 1994.

[33] G. Imbens and K. Kalyanaraman, "Optimal bandwidth choice for the regression discontinuity estimator," Review of Economic Studies, vol. 79, no. 3, pp. 933-959, 2012. 